\title{
Intrahepatic Biliary Obstruction in Congenital Bile Duct Atresia
}

\author{
Ryoji Oh-i and Morio Kasai \\ The Second Department of Surgery (Prof. M. Kasai), \\ Tohru Takahashi \\ The First Department of Pathology (Prof. N. Suwa), \\ Tohoku University School of Medicine, Sendai
}

\begin{abstract}
The three-dimensional structure of small intrahepatic bile ducts in congenital biliary atresia was examined by graphical reconstruction of serial histological sections. In the disease, intrahepatic bile duct system was constituted by an extremely complex network of proliferating bile ductules. Bile duct proliferation was interpreted as a reaction of the bile system to bile stagnation and bile leakage in the portal area. The restoration of a patent intrahepatic bile system seemed to depend upon the preservation of 'main routes' of bile passage, which probably belonged to the pre-existing bile duct system. The maintenance of anatomically recognizable main routes could be correlated with the clinical effect of extrahepatic bile duct plasty.
\end{abstract}

Congenital bile duct atresia is characterized by obstruction of bile passage from the liver to the duodenum due to some malformation of the biliary system. The malformation ranges from segmental obstruction to complete aplasia of the extrahepatic bile ducts. In some extreme cases microscopic examination of the liver fails to show the biliary epithelium throughout the portal tracts. The condition is commonly. called intrahepatic biliary atresia ${ }^{1-3}$ and is not feasible to surgical correction. Since the statistical work of Holmes (1916), ${ }^{4}$ surgical correctability of biliary atresia was discussed by many authors in relation to the anatomical type of malformation. Recently, hepatic portoenterostomy was introduced by Kasai et al. ${ }^{5}$ into the treatment and extended surgical indication of the disease.

However, postoperative prognosis of congenital biliary atresia is various from case to case, irrespective of the type of malformation and no matter what operative method is employed. Moreover, it is well known that the results of surgical correction depend widely upon the age and the duration of jaundice of the diseased children. ${ }^{6,7}$ According to the authors' experience, the operation performed on patients over 4 months of age does not bring about any relief of jaundice. This indicates that jaundice in these patients is due not only to the malformation of extrahepatic ducts, but also to some pathological changes within the liver. The latter mechanism will be designated as 'intrahepatic factor of bile stasis' in the present report.

Received for publication, June 3, 1969. 
The liver in congenital biliary atresia undergoes a change that leads in a word to biliary cirrhosis. Microscopical examination of the liver discloses severe cholestasis in the ductal and ductular system, followed by leakage of bile into the interstitial tissue. This produces periductular inflammation which results in portal fibrosis on one hand and causes new destruction of bile ductules on the other. Thus one can see a vicious cycle proceeding in the liver, which must play an important role in making jaundice in the disease untractable. The diversity in the postoperative course of jaundice will be attributable to variable degrees of disintegration of the intrahepatic biliary system. It is the purpose of the present investigation to analyze the intrahepatic mechanism of bile stasis in congenital biliary atresia in relation to its clinical manifestations.

Considered from this viewpoint, some indicator is necessary for expressing the grade of intrahepatic involvement. The authors estimated histometrically the volume of interstitial tissue in a unit volume of the liver, the interstitial-volume ratio $V_{i}$, for each case. This quantity serves as an index of hepatic fibrosis or the grade of biliary cirrhosis.

In the next place, the structural changes of intrahepatic biliary system are to be analyzed. It is needless to say that so-called pseudoductules are found abundantly in the periportal area in most of the cases of biliary cirrhosis. However, the evaluation of functional potency of proliferating ductules awaits further analysis. Through a histometrical procedure, the authors estimated the total length of the ductules in a unit volume of the liver $\left(L_{d}\right)$, and thus quantitatively determined the degree of ductular proliferation. Functional meaning of the ductular proliferation may be elucidated by comparing the quantity $L_{d}$ of individual cases with clinical findings.

It is expected that the destruction of the intrahepatic ductular system would cause a pronounced derangement in the structure of the system and an impediment to bile passage. Such a derangement was demonstrated recently by Takahashi and Hayama ${ }^{8}$ in cases of cholestatic jaundice without extrahepatic obstruction. If there is serious deficiency in the continuity of the ductular system as a whole, bile cannot be sufficiently excreted, no matter how abundant proliferation of ductules may take place in the periportal area. The authors performed graphic reconstruction of the cholangiolar system by means of serial histological sections of the liver and examined the nature of the structural changes of the system. Available cases of congenital biliary atresia were divided into two groups according to the effect of operation on jaundice. Typical cases were selected from the groups and were submitted to the three-dimensional analysis. On the basis of the results obtained, the nature of the intrahepatic factor of bile stasis in these cases will be discussed.

\section{Materials and Methods}

Liver tissue specimens from 36 patients of 63 to 292 days of age were used for this study. All the patients had malformations of extrahepatic bile ducts of various types. 
Thirty-four out of 36 cases were treated at the Second Surgical Clinic, the remaining two at the Pediatric Clinic, Tohoku University Hospital. Among the former, 30 cases were submited to operation. In 21 out of 36 cases tissue specimens were obtained at autopsy and in the other cases by excision at laparotomy. Besides, 'normal' livers in 8 autopsy cases of 18 to 197 days of age were selected for control. Tissue slices were fixed in Zenker-formalin or in formalin solution and embedded in paraffin.

Histological sections were prepared from each paraffin block at $3 \mu$ in thickness and stained with Heidenhein-Mallory stain, which ensured the best discrimination of the hepatic parenchyma from the fibrotic area, as well as the ductules from the surrounding interstitium. The sections were used for the estimation of $V_{i}$ and $L_{d}$.

$V_{i}$, the volume of interstitial tissue in a unit volume of the liver, or the interstitial volume ratio, is estimated by line sampling on histological sections of the liver. When a sampling line of $l$ in length is drawn on a histological section, this traverses fibrotic area several times and generates linear intercepts of various length $I_{i}$ (Fig. 1). When $I_{i}$ is measured microscopically on all the linear intercepts produced by the fibrotic area, interstitial volume ratio $V_{i}$ of the liver is given by:

$$
V_{i}=\frac{\Sigma I_{i}}{l}
$$

The techniques of histometry are described in detail in the foregoing papers., ${ }^{90}$ In this study, measurement was performed in each case with a sampling line of 5 to $10 \mathrm{~cm}$ in total length, which was sufficient to yield a fairly constant estimation of $V_{i}$.

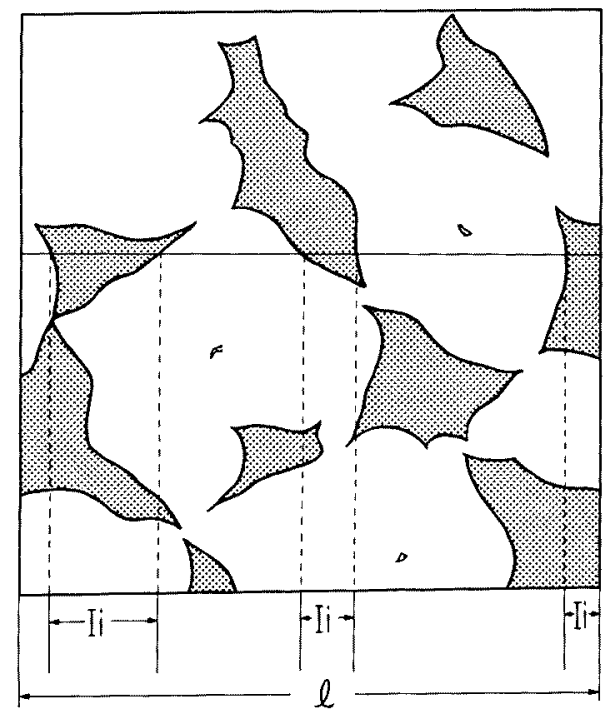

Fig. 1. Line sampling for the estimation of $V_{i}$. A sampling line of $l$ in length traverses fibrotic area three times in the figure and generates linear intercepts of various length $I_{i}$.

For the estimation of $L_{d}$, the total length of the ductules in a unit volume of the liver, the following mathematical principle was applied. Suppose a sufficiently large cube of liver tissue with edges of $l^{\prime}$ in length. It is now assumed that the cube is cut by an arbitrary plane which is parallel to any one side of the cube. The plane cuts the ductules at various points, and sections of ductules are generated on the plane of $l^{\prime 2}$ in area (Fig. 
2). If the number of sections on that plane amounts to $n$, the total length of ductules $L^{\prime}$ in the cube is estimated by:

$$
L^{\prime}=2 n \cdot l^{\prime}
$$

and consequently one obtains:

$$
L_{d}=\frac{2 n \cdot l^{\prime}}{l^{\prime 3}}=\frac{2 n}{l^{\prime 2}}
$$

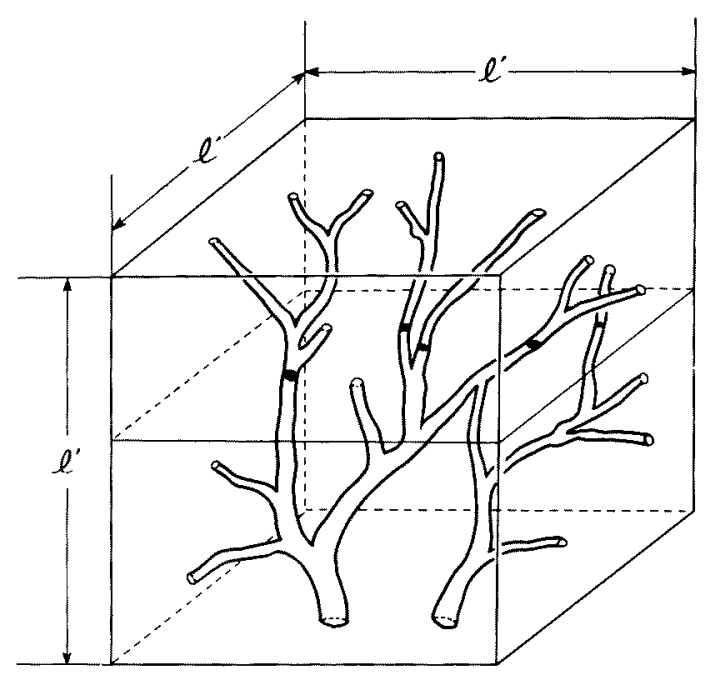

Fig. 2. Plane sampling in the estimation of $L_{d}$. A cube of liver tissue with edges of $l^{\prime}$ in length is cut by an arbitrary plane which is parallel to any one side of the cube. The plane cuts the ductules at 5 points in the figure, and consequently $n=\mathbf{5}$.

The derivation of the expression is described in the paper of Arai et $a .^{11}$ If a sufficiently large volume of the liver tissue is taken into consideration, the ductules in the volume are regarded as randomly distributed in their direction. Accordingly, the above relation is directly applicable for the estimation of $L_{d}$. A histological section of the liver of $S$ in area serves as an equivalent to a square sampling plane with edges of $\sqrt{ } S$. In this manner, $L_{d}$ is estimated by counting the number of transections of ductules on a histological slide of the liver.

The graphic reconstruction of the ductular system was performed on three selected cases of congenital biliary atresia. All of the three patie.ats had been submitted to surgical establishment of the extrahepatic bile drainage. In two of them, Cases 1 and 2 in the following, the operation was quite successful, and jaundice disappeared and prognosis was favorable. In Case 3 no effect was brought about by the operation. For the control, the liver of a 2-month-old infant was examined.

The liver specimens for reconstruction were fixed in Zenker-formalin solution, embedded in celloidin-paraffin, and serial sections were prepared from each specimen at $6 \mu$ in thickness. 200 serial sections from each block met the requirement of this study. The sections were stained with Heidenhein-Mallory stain. With regard to the graphic reconstruction, the same method was applied as that described by Takahashi and Hayama. ${ }^{8}$ A portal tract about $200 \mu$ in breadth was selected. This was projected under high magnification on tracing paper, and all the ducts and ductules within the portal tract were drawn. The drawings were placed one upon another in series, and the architecture of the ductular system was examined. The mutual relationship of the individual ductular segments was examined on all the ductules appeared in the drawings. Through this procedure, the 
authors prepared a stereogram, a side view of the ductular system in the portal tract. In this paper, architecture of the ductular system in the individual cases will be illustrated by means of the stereogram.

\section{Results and Discussion}

The available 36 cases were divided into three groups according to their clinical courses. Such a division facilitates the examination of the correlation of hepatic changes to the effect of operation on jaundice.

Group 1: 11 cases. Stools became normally bile-stained and jaundice was reduced after the operation. These cases were regarded as those of improvement by the operation. In two out of the eleven cases jaundice disappeared completely, serum bilirubin content turned to normal level, and recovery was ascertained clinically. In the remaining eight cases, serum bilirubin was sustained at a somewhat higher level than normal after the operation, although there was remarkable improvement in their general conditions. Four of these patients died of unexpected complications in the convalescence.

Group 2: 19 cases. Clinical status showed little change after the operation with persistence of severe jaundice and high serum bilirubin content. They were regarded as intractable by the operation. Most of these patients died within one year.

Group 3: 6 cases. Surgical operation could not be done on account of unfavorable general conditions. They were treated conservatively until death.

\section{1) The age of patients at operation and postoperative course}

The mean age of patients at operation can be calculated from Table 1 with regard to groups 1 and 2 . In group 1, the mean age at operation is 79.1 days, and in group 2, 139.4 days. The difference between the means is significant at a level of 0.001 . This result agrees to the general opinion that the younger the patient, the better the result of operation, and vice versa. The upper rejection limit of age in group 1 is 115.8 days. Accordingly, it may hardly be expected to relieve the patients over 4 months of age from distress by means of surgical correction.

\section{2) Results of histometrical treatments}

Estimation of the interstitial volume ratio $V_{i}$ in each case is listed in Table 1 and demonstrated in Fig. 3 for comparison between groups 1 and 2 and normal group. At a glance one can see in the figure that $V_{i}$ is evidently larger in both the groups of congenital biliary atresia than in the normal group. In the latter, $V_{i}$ is kept below 0.1 , the mean of $V_{i}$ being 0.081 . It is further noteworthy that the deviation of estimates is quite small in normal subjects and $V_{i}$ remains almost unchanged during the period of infancy.

In Fig. 4, the estimates of $V_{i}$ of all the 36 cases of congenital biliary atresia are plotted against ages when the specimens were obtained. Here, the correlation 
TABLE 1.

\begin{tabular}{|c|c|c|c|c|c|}
\hline & Case & $\begin{array}{l}\text { Age in da } \\
\text { and sex }\end{array}$ & $y^{*}$ & $V_{i}$ & $L_{d}\left(\mathrm{~mm} / \mathrm{mm}^{3}\right)$ \\
\hline Group 1 & $\begin{array}{l}\text { S.H. } \\
\text { R.A. } \\
\text { T.A. } \\
\text { T.K. } \\
\text { Y.F. } \\
\text { Y.S. } \\
\text { M.K. } \\
\text { Y.H. } \\
\text { K.K. } \\
\text { M.Y. } \\
\text { T.M. }\end{array}$ & $\begin{array}{c}81(81) \\
72(72) \\
160(60) \\
85(82) \\
119(109) \\
63(63) \\
76(76) \\
90(90) \\
70(70) \\
66(66) \\
101(101)\end{array}$ & $\begin{array}{l}\mathrm{F} \\
\mathrm{F} \\
\mathrm{M} \\
\mathrm{F} \\
\mathrm{F} \\
\mathrm{F} \\
\mathrm{F} \\
\mathrm{M} \\
\mathrm{F} \\
\mathrm{F} \\
\mathrm{M}\end{array}$ & $\begin{array}{l}0.314 \\
0.401 \\
0.426 \\
0.157 \\
0.175 \\
0.215 \\
0.220 \\
0.277 \\
0.391 \\
0.346 \\
0.309\end{array}$ & $\begin{array}{l}26.8 \\
57.1 \\
32.6 \\
13.3 \\
11.3 \\
22.8 \\
30.5 \\
59.5 \\
72.4 \\
43.1 \\
35.5\end{array}$ \\
\hline Group 2 & $\begin{array}{l}\text { M.M. } \\
\text { K.S. } \\
\text { C.T. } \\
\text { J.U. } \\
\text { M.N. } \\
\text { S.K. } \\
\text { S.H. } \\
\text { T.I. } \\
\text { K.A. } \\
\text { K.I. } \\
\text { H.I. } \\
\text { A.O. } \\
\text { Y.S. } \\
\text { N.M. } \\
\text { M.A. } \\
\text { M.S. } \\
\text { Y.T. } \\
\text { N.I. } \\
\text { N.H. }\end{array}$ & $\begin{array}{l}153(135) \\
159(130) \\
109(63) \\
180(149) \\
187(155) \\
236(232) \\
292(98) \\
105(104) \\
209(117) \\
165(91) \\
228(205) \\
192(181) \\
141(136) \\
240(240) \\
176(176) \\
126(126) \\
92(92) \\
95(95) \\
124(124)\end{array}$ & $\begin{array}{l}F \\
F \\
F \\
M \\
F \\
F \\
F \\
M \\
M \\
F \\
F \\
F \\
F \\
F \\
F \\
M \\
F \\
M \\
M\end{array}$ & $\begin{array}{l}0.490 \\
0.524 \\
0.413 \\
0.336 \\
0.576 \\
0.426 \\
0.638 \\
0.451 \\
0.476 \\
0.417 \\
0.508 \\
0.382 \\
0.620 \\
0.227 \\
0.205 \\
0.404 \\
0.279 \\
0.407 \\
0.420\end{array}$ & $\begin{array}{r}73.3 \\
51.4 \\
47.5 \\
34.6 \\
80.4 \\
44.7 \\
87.4 \\
102.7 \\
58.1 \\
105.9 \\
54.1 \\
75.5 \\
76.3 \\
58.2 \\
33.8 \\
51.8 \\
30.6 \\
42.6 \\
49.6\end{array}$ \\
\hline Group 3 & $\begin{array}{l}\text { T.K. } \\
\text { H.K. } \\
\text { Y.S. } \\
\text { S.T. } \\
\text { H.T. } \\
\text { M.O. }\end{array}$ & $\begin{array}{r}266 \\
65 \\
187 \\
74 \\
179 \\
165\end{array}$ & $\begin{array}{l}\mathrm{M} \\
\mathrm{M} \\
\mathrm{F} \\
\mathrm{F} \\
\mathrm{F} \\
\mathrm{F}\end{array}$ & $\begin{array}{l}0.383 \\
0.236 \\
0.401 \\
0.259 \\
0.329 \\
0.482\end{array}$ & $\begin{array}{l}33.1 \\
22.2 \\
50.7 \\
35.6 \\
55.9 \\
73.8\end{array}$ \\
\hline Normal & $\begin{array}{l}\text { N. } 1 \\
\text { N. } 2 \\
\text { N. } 3 \\
\text { N. } 4 \\
\text { N. } 5 \\
\text { N. } 6 \\
\text { N. } 7 \\
\text { N. } 8\end{array}$ & $\begin{array}{r}45 \\
47 \\
197 \\
166 \\
18 \\
70 \\
18 \\
104\end{array}$ & $\begin{array}{l}F \\
M \\
M \\
F \\
F \\
F \\
M \\
M\end{array}$ & $\begin{array}{l}0.081 \\
0.071 \\
0.095 \\
0.072 \\
0.094 \\
0.082 \\
0.072 \\
0.082\end{array}$ & $\begin{array}{r}8.5 \\
6.2 \\
7.9 \\
6.4 \\
9.9 \\
9.0 \\
8.6 \\
10.6\end{array}$ \\
\hline
\end{tabular}

* The ages of patients when liver specimens were obtained. Put in parentheses are the ages at operation. 


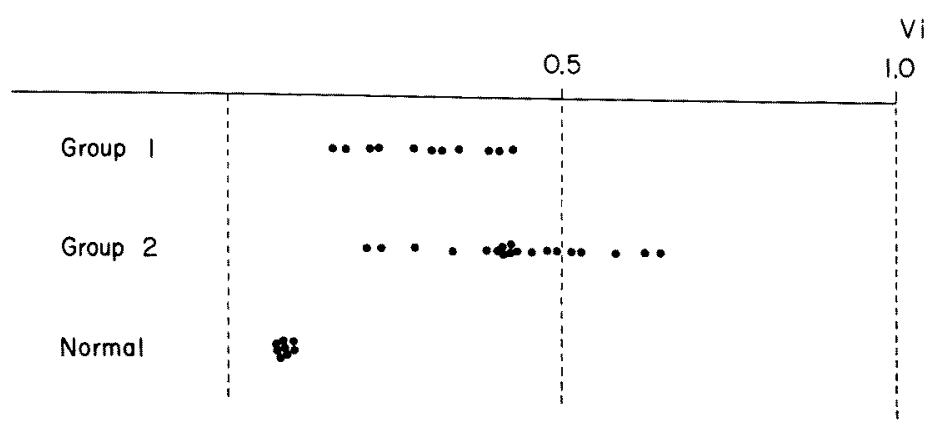

Fig. 3. Estimates of the interstitial-volume ratio $V_{i}$ in groups 1 and 2 and normal group.

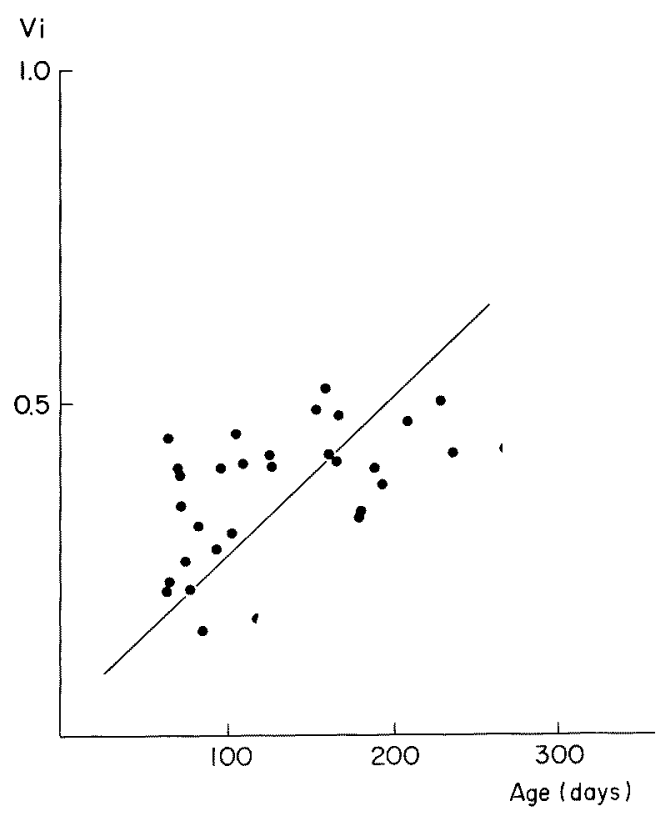

Fig. 4. $V_{i}$ in relation to ages. Note a positive correlation between $V_{i}$ and age in livers of congenital biliary atresia.

coefficient between $V_{i}$ and age is calculated at 0.48 , a positive correlation significant at $1 \%$ level. This correlation suggests the progressive nature of fibrosis in these livers. Since biliary cirrhosis in cases of congenital biliary atresia advances without reformation of the lobular structure, interstitial volume ratio will be the only index of the development of biliary cirrhosis. Moore ${ }^{12}$ reported a newborn infant with congenital biliary atresia, whose liver presented no sign of bile retention, much less fibrosis, in the periportal spaces. This report being taken into account, the above result may indicate that the intrahepatic changes start at birth, aggravate with age and lead finally to biliary cirrhosis. 
The view is supported by the difference in $V_{i}$ between the groups 1 and 2 of congenital biliary atresia. As is seen in Fig. 3 and Table 2, the sample mean of $V_{i}$ is smaller in group 1 improved by operation than in group 2 of unchanged or aggravated jaundice after operation. Statistical test proves a difference between the means significant at $1 \%$ level (Table 3). Five cases in Table 1, i.e., T.A. in group 1, C.T., S.H., K.A., and K.I. in group 2, are excluded from the statistical analysis, because the interval between surgical operations and histological examinations of the liver specimens seems too long. It is quite conceivable from the result that the intrahepatic process, or the process leading to biliary cirrhosis, is more advanced in group 2 than in group 1. At the same time this explains the foregoing results that the average age at operation is lower in group 1 than in group 2. The patients in group 1 must have been operated on before the intrahepatic changes attained a certain critical stage.

Table 2.

\begin{tabular}{l|c|c|c|c|c}
\hline & $N$ & \multicolumn{2}{|c|}{$X=V i$} & \multicolumn{2}{|c}{$X=L d$} \\
& & $\bar{x}$ & $S x^{2}$ & $\bar{x}$ & $S x^{2}$ \\
\hline Group 1 & 10 & 0.2805 & 0.067298 & 37.23 & 3772.46 \\
Group 2 & 15 & 0.4170 & 0.200938 & 57.31 & 5833.69 \\
Group 3 & 6 & 0.3483 & 0.042815 & 45.22 & 1730.27 \\
Normal & 8 & 0.0811 & 0.000629 & 8.39 & 16.59
\end{tabular}

TABLE 3 .

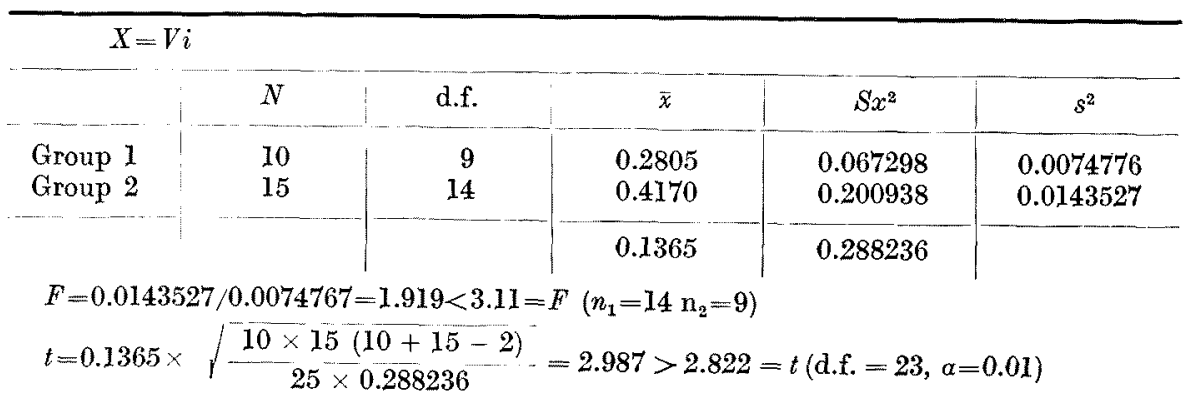

It is shown by the above results that operation fails to drain bile in advanced cases. This indicates an obstructive mechanism in the intrahepatic draining system, which prevails with the progress of biliary cirrhosis. In the next place, therefore, the behavior of the intrahepatic ductular system in these cases is taken into consideration.

In Fig. 5, estimates of $L_{d}$, the total length of ductules in a unit volume $\left(1 \mathrm{~mm}^{3}\right)$ of the liver, are demonstrated in $\mathrm{mm}$. The mean $L_{d}$ of 8 normal livers is $8.4 \mathrm{~mm} /$ $\mathrm{mm}^{3}$, and the variation of estimates is quite small. In all of the 3 groups of congenital biliary atresia, $L_{d}$ is evidently larger than in the normal group. This is due to an active proliferation of bile ductules in the livers in this disease. 


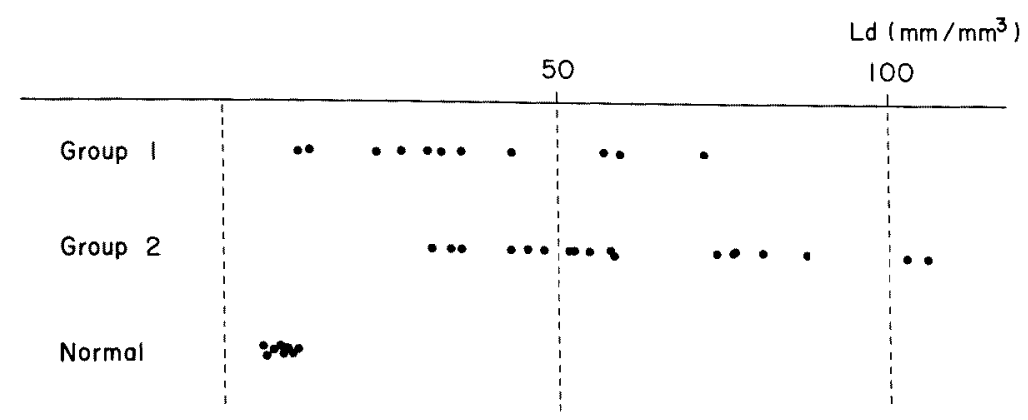

Fig. 5. Estimates of the total length of ductules in a unit volume $\left(1 \mathrm{~mm}^{3}\right)$ of the liver $L_{d}$ in groups 1 and 2 and normal group.

On the other hand, one may see in Fig. 5 that $L_{i}$ is larger on the whole in group 2 than in group 1. The difference in the means between the two groups is statistically significant at $1 \%$ level (Table 4 ).

TABLE 4.

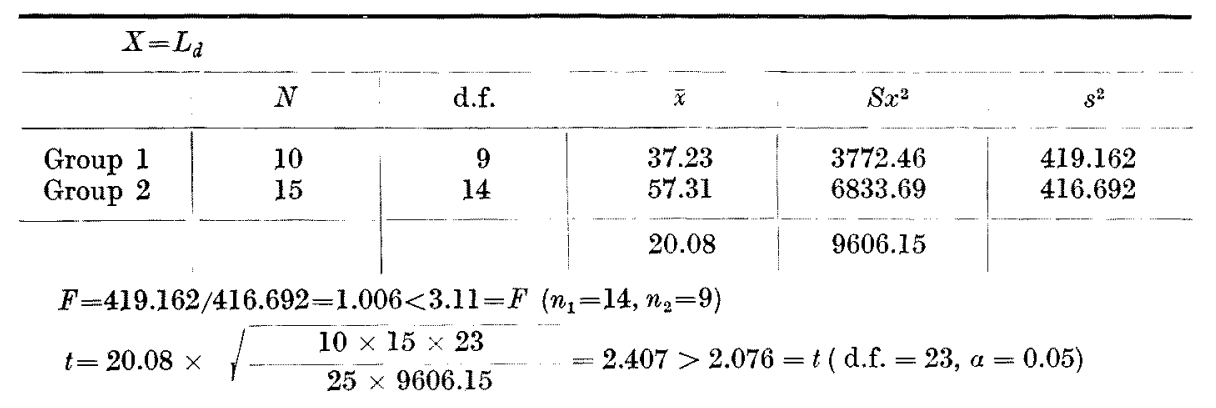

There has been much discussion on the functional meaning of bile duct proliferation in biliary cirrhosis of infants. Sterling ${ }^{13}$ regarded the proliferation of ductules as helpful to bile drainage and assumed that proliferating ductules finally restored the biliary routes in some way. However, according to the result of the present study, $L_{d}$ is relatively small in most of the improved patients (group 1). Therefore, active proliferation of ductules must be taken for a manifestation of impaired bile drainage in the intrahepatic biliary routes. At least it may be said safely that good prognosis can be expected in cases with slight degree of fibrosis and less pronounced ductular proliferation.

The values of $V_{i}$ and $L_{d}$ of all cases in the three groups of biliary atresia as well as in the normal group are demonstrated in Fig. 6 in the form of correlation on a coordinate system. Here one can see a close correlation between $V_{i}$ and $L_{d}$. The correlation coefficient is 0.73 and significant at $0.1 \%$ level. Ductular proliferation becomes more pronounced in proportion to the progress of biliary cirrhosis. 


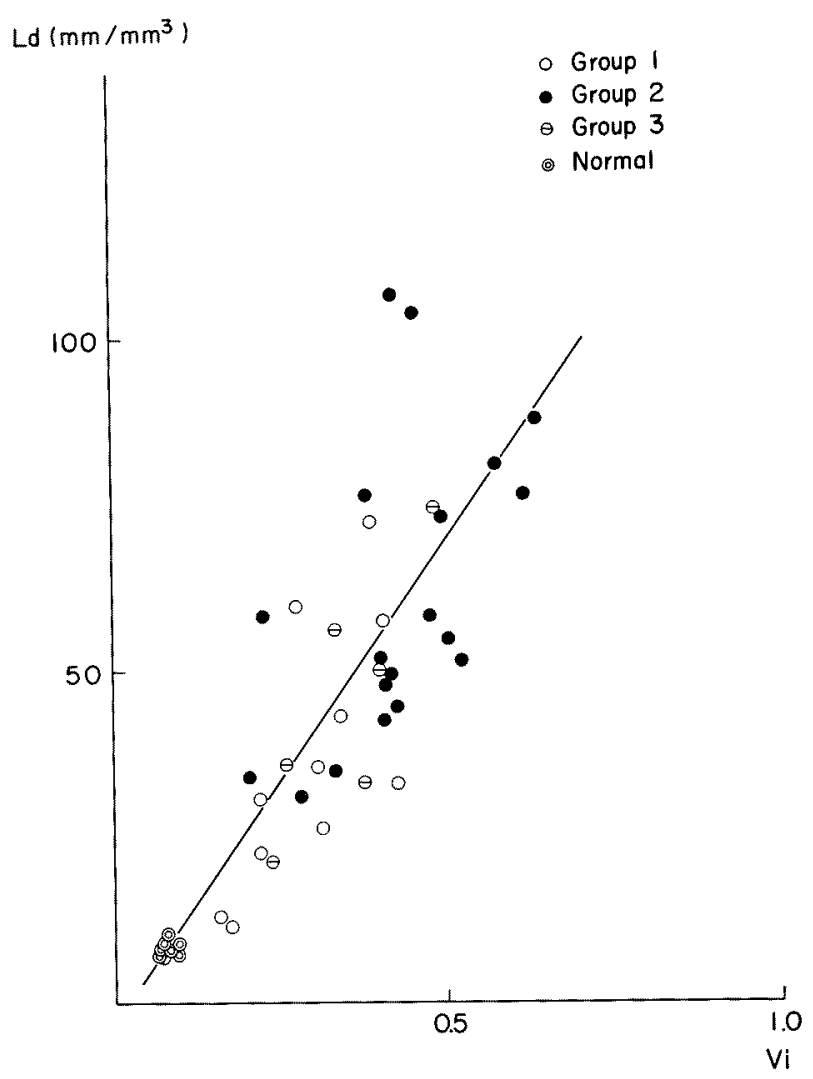

Fig. 6. Correlation between $V_{i}$ and $L_{d}$. One can see a close correlation between $V_{i}$ and $L_{d}$.

On the basis of these results, it is quite improbable that newly formed ductules are connected together to form a continuous system fully capable of draining bile from every portion of the liver. Microscopical examination of such livers never fails to reveal a marked periportal inflammation and subsequent fibrosis of the region. It is easily conceivable that under these circumstances the ductules are crushed or broken up. Thus, the ductular proliferation is rather a blind regeneration of ductular or hepatic cells, which is interpreted merely as a sign of bile stasis in the duct system. However, the whole architecture of the ductular system cannot be analyzed with routine histological technique. The relationship of the newly formed ductules and pre-existing ducts will be demonstrated only through threedimensional reconstruction of the system.

3) Architecture of the ductular system

In the first place, information is necessary about the three-dimensional structure of the ductular system in the normal liver. A liver specimen from an infant aged 2 months, who died of collapse due to insufficiency of the adrenal 
cortex, was selected for control. The liver weighed $190 \mathrm{~g}$ and there was no gross anatomical nor histological change. The reconstruction was performed with special attention to the continuity of ductular segments, in other words, to the patency of the bile draining system.

In Fig. 7, graphic reconstruction of ductules in a segment of portal tract of about $300 \mu$ in diameter is demonstrated. The ductular system is so illustrated that the ductules are deprived of all the surrounding tissue elements. One can see in the figure a ductal trunk running in longitudinal direction. This is the chief draining route in the portal tract examined and will be called the main interlobular duct or the main draining route. Some minor branches are seen originating from the main interlobular duct, and these are separated into several end branches which terminate at the liver cell plate surrounding the portal tract-the limiting plate. The points where terminal ductules are connected with the limiting plate are presented in the figure in the form of smeared ends.

The structure of ductular system is quite simple in the normal liver, and excretory routes are clearly organized. Continuity of ductular segments is perfectly ensured in the whole area. In comparison with the result, typical cases of biliary atresia will be presented as follows.

Case 1 (group 1). S.H., female, 81 days old at operation.

The mother of the patient was in good health during the pregnancy. The birth weight was $3,450 \mathrm{~g}$. Jaundice was noticed about 20 days after birth, and the child was admitted to the Pediatric Clinic of the Tohoku University Hospital on July 21, 1966. On admission, she appeared fair except for jaundice. The liver was palpable 2.5 fingers' breadth below the right costal margin. The urine was dark and the stools were light in color. Examination of the blood disclosed a red cell count of 3.68 millions, $62 \%$ hemoglobin and a white cell count of 15,525 . The total serum cholesterol was $228 \mathrm{mg} / \mathrm{dl}$.

The operation performed 81 days after birth disclosed perfect obliteration of extrahepatic bile ducts. The liver was soft and dark brown to somewhat greenish in color. The gallbladder was hypoplastic. From these anatomical findings, the anomaly in this patient was of incorrectable type, or of the third type of Kasai's classification. ${ }^{5}$ Hepatic portojejunostomy with Roux-Y anastomosis was carried out. The postoperative course was uneventful. The liver function tests before and after the operation are listed in Table 5. The serum bilirubin content decreased drastically after the operation. The stool became yellowish in color and jaundice disappeared by degrees. The patient was discharged 44 days after the operation.

The histological picture of the liver specimen obtained at operation is presented in Figs. 8 and 9. Portal spaces are moderately widened on account of fibrosis accompanied with inflammatory reactions. Although multinucleated liver cells are found in a large number, there is no sign of liver cell damage in the lobular parenchyma. A few bile plugs are noticed in the dilated bile canaliculi. 


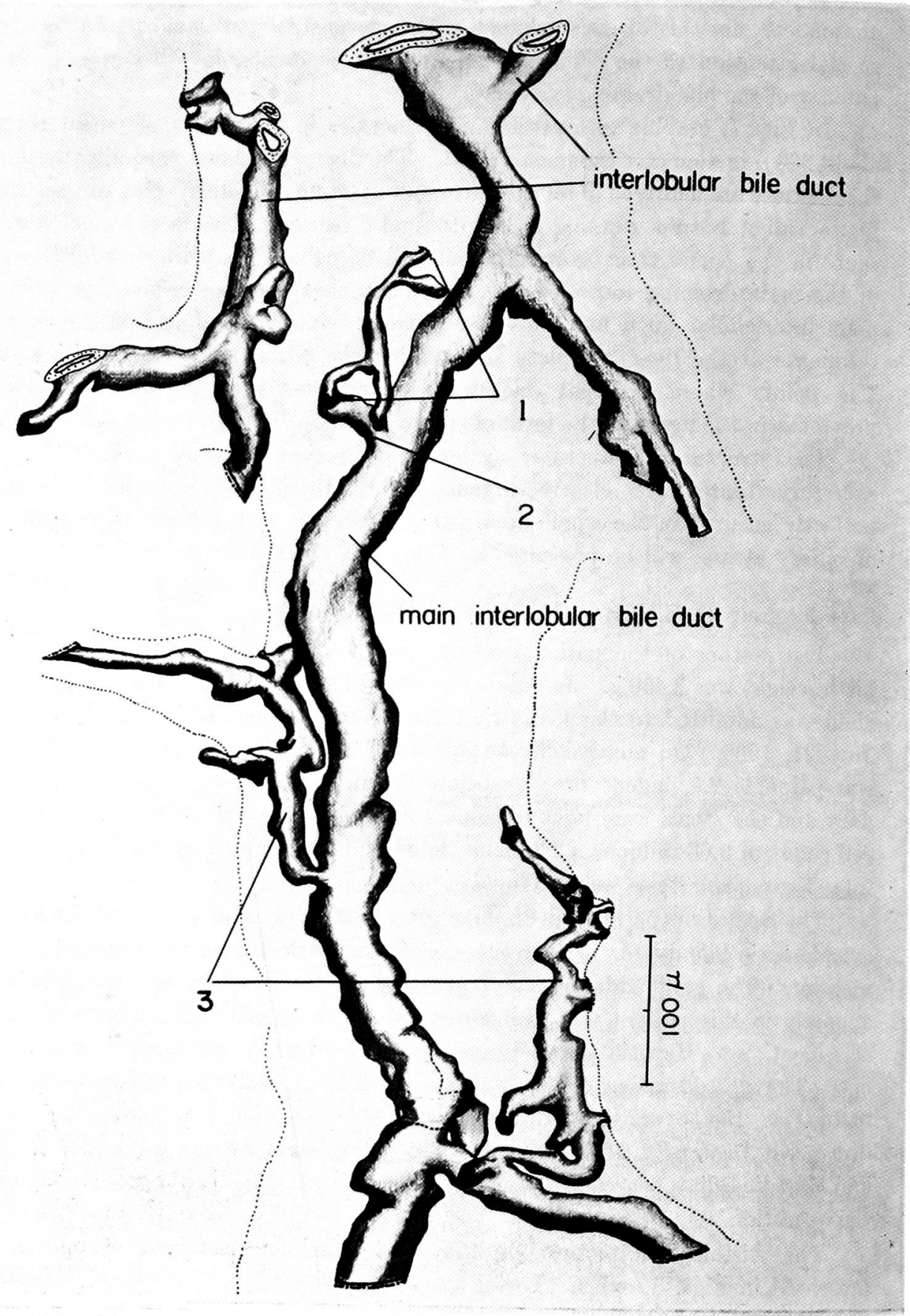

Fig. 7. A graphic reconstruction of the normal portal tract. One can see in the figure a ductal trunk running in longitudinal direction which will be called the main interlobular duct or the main draining route. 1 : connection between terminal ductules and the limiting plate. 2: junction of minor branch with the main interlobular duct. 3: minor branches of bile ducts. 
TaBle 5. Liver function tests in Case 1

\begin{tabular}{|c|c|c|c|c|c|c|c|c|}
\hline & \multicolumn{2}{|c|}{ Bilirubin (mg/dl) } & \multirow{2}{*}{ CCFT } & \multirow{2}{*}{ ZTT } & \multirow{2}{*}{ TTT } & \multirow{2}{*}{ SGOT } & \multirow{2}{*}{ SGPT } & \multirow{2}{*}{$\begin{array}{c}\text { Alkaline } \\
\text { phosphatase } \\
\text { (K.A. unit) }\end{array}$} \\
\hline & Total & Direct & & & & & & \\
\hline $\begin{array}{ll}\text { Aug. } & 1 \\
\text { Aug. } & 8\end{array}$ & \multicolumn{2}{|c|}{ Operation } & $(-)$ & 0.4 & 0.2 & 120 & 54 & 40.3 \\
\hline Aug. 26 & 1.6 & 0.9 & $(-)$ & 1.4 & 1.9 & 79 & 53 & - \\
\hline Sep. 12 & 2.2 & 1.4 & $(-)$ & 0.2 & 0.7 & 41 & 26 & 23.5 \\
\hline
\end{tabular}

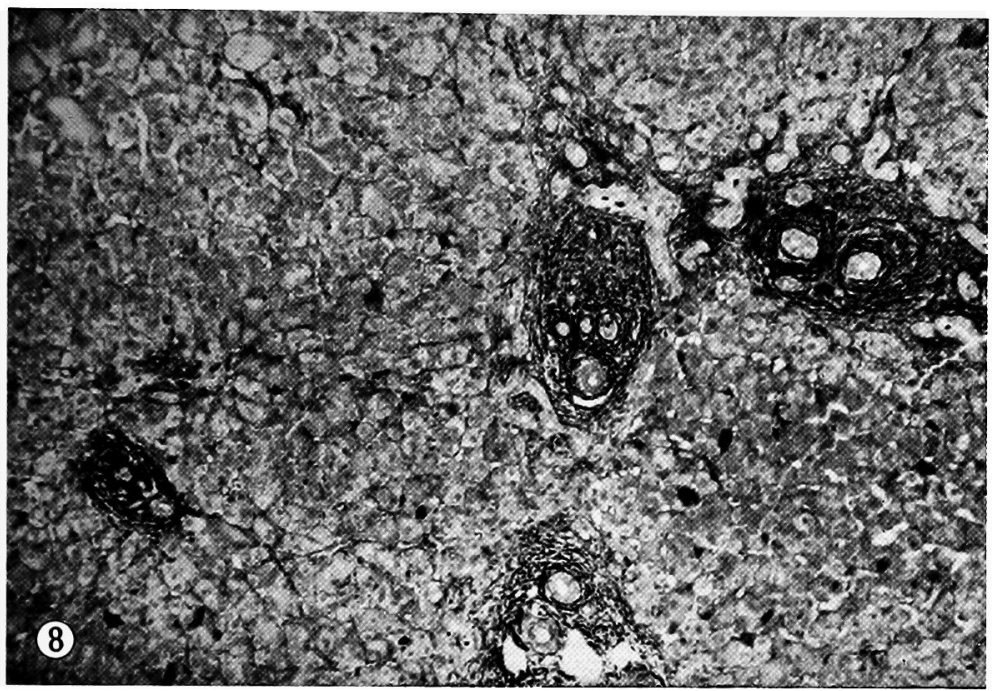

Fig. 8. Photomicrograph of the liver in Case 1.

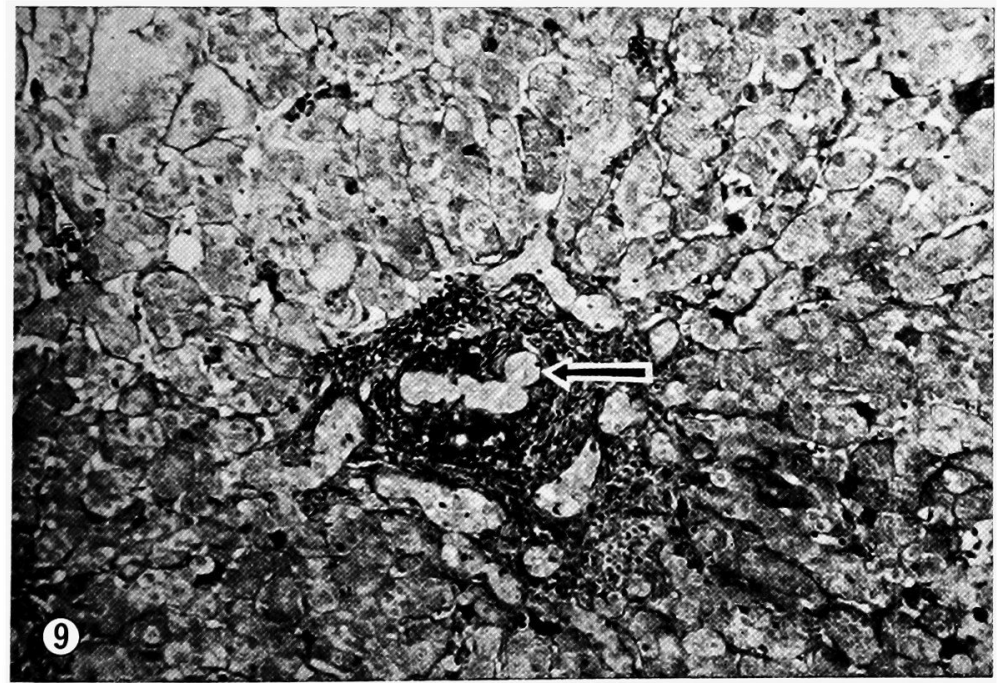

Fig. 9. The portal tract selected for reconstruction of ductules in Case 1. A medium-sized bile duct can be seen in the center of the portal space (arrow). Connections of bile ducts with liver cells are easily found out. 
Fig. 9 shows the portal tract which is selected for reconstruction of ductules. There is a pronounced ductular proliferation in the periportal zone along the limiting plate. Bile plugs are found in some of the newly formed ductules. Besides, one can see a medium-sized bile duct in the center of the portal space (pointed by arrow). As will be mentioned in the following, this is the main duct in the portal tract. It deserves special attention that main interlobular ducts are kept intact in most of the portal tracts in this liver.

The result of reconstruction is exhibited in Fig. 10. There is vigorous ductular proliferation, which constitutes a complicated network of ductules. This complexity in architecture presents a striking contrast to the plain pattern of the normal ductular system. However, one can find out a prominent pathway running longitudinally in the center of the figure. The character of the epithelial lining (Fig. 9) and spatial relationship to the ductular network indicate that this duct is properly regarded as the main draining route of the portal tract. The proliferating ductules are connected with one another in all directions, and there are numerous anastomoses between these and the limiting plate. This structure suggests that the ductular network originated in epithelial buddings from the limiting plate. As is shown in the figure, the ductular network has connections

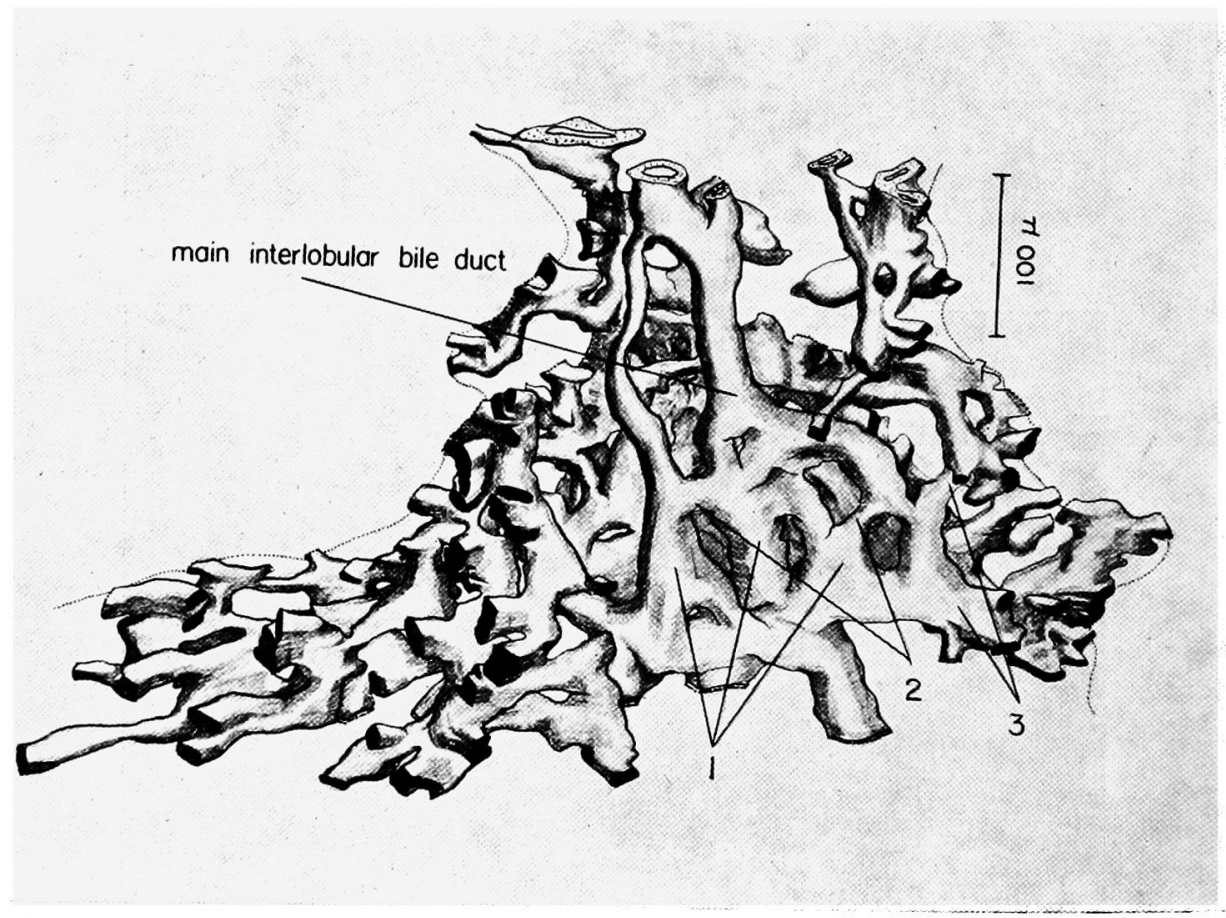

Fig. 10. A graphic reconstruction of the portal tract in case 1. Note a vigorous ductular proliferation. However, draining routes are kept sufficiently maintained by the presence of interlobular bile ducts in this case. 1: several branches of the main draining route. 2: anastomoses between the main draining route. 3 : connections of main draining route with proliferated ductules. 
with the main duct at several points. Thus the anatomical pattern of the ductular system indicates that draining routes are sufficiently maintained in this case.

Case 2 (group 1). R.A., female, 72 days old at operation.

The mother of the patient suffered from toxemia of pregnancy in the later period of gestation. The delivery was full term and normal. The birth weight was $3,400 \mathrm{~g}$. Jaundice appeared about 2 weeks after birth, and the child was admitted to the Second Surgical Clinic of Tohoku University Hospital. On admission, she had a marked jaundice but was otherwise in a fairly good condition. The liver extended 2.5 fingers' breadth below the right costal margin. No xanthoma nor dilatation of subcutaneous vein was seen. The stool examinations were negative for Schmidt's test. The urine was positive for Gmelin's test. Examination of the blood disclosed 3.39 millions of red cells, $72 \%$ hemoglobin and 18,850 white cells. The total serum cholesterol was $184 \mathrm{mg} / \mathrm{dl}$. The operation performed on the 72nd day of life revealed total obliteration of extrahepatic bile ducts. The liver was dark brown in color and tough in consistency. The gallbladder was very small without lumen. These anatomical findings corresponded to the malformation of the third type of Kasai. Hepatic portojejunostomy with Roux-Y anastomosis was performed. The postoperative course of the patient was uneventful except for a slight superficial infection. Bile appeared in the intestinal content after the operation and jaundice gradually diminished in degree. The results of liver function tests before and after the operation are given in Table 6 . After the operation, both total and direct bilirubin contents in serum decreased to half the preoperative level. On the contrary, a marked increase in serum alkaline phosphatase was noted. She was discharged 57 days after the operation.

TABLE 6. Liver function tests in Case 2

\begin{tabular}{|c|c|c|c|c|c|c|c|c|}
\hline & \multicolumn{2}{|c|}{ Bilirubin $(\mathrm{mg} / \mathrm{dl})$} & \multirow{2}{*}{ CCFT } & \multirow{2}{*}{ ZTT } & \multirow{2}{*}{ TTT } & \multirow{2}{*}{ SGOT } & \multirow{2}{*}{$\mathrm{SGPT}$} & \multirow{2}{*}{$\begin{array}{c}\text { Alkaline } \\
\text { phosphatase } \\
\text { (K.A. unit) }\end{array}$} \\
\hline & Total & Direct & & & & & & \\
\hline Jun. 22 & 14.6 & 11.0 & - & 0.6 & 0.7 & 200 & 250 & 27.7 \\
\hline Jul. 11 & \multicolumn{2}{|c|}{ Operation } & & & & & & \\
\hline Jul. 20 & 6.4 & 4.7 & - & 1.8 & - & 155 & $\begin{array}{r}70 \\
750\end{array}$ & $\begin{array}{l}41.0 \\
80.0\end{array}$ \\
\hline Aug. 15 & 6.4 & 4.8 & - & 2,0 & 3.4 & 240 & 150 & \\
\hline
\end{tabular}

Histological examination of the liver specimen discloses marked periportal fibrosis which has extended irregularly and linked the adjacent portal spaces (Fig. 11). There is moderate ductular proliferation in the periportal zones. As is shown in Fig. 12, however, the main duct is clearly recognized (arrow) in the dense mass of collagenous tissue which represents the original structure of a Glisson's sheath.

Fig. 13 shows the result of reconstruction. There is an abundant proliferation of ductules in the form of a dense ductular network. But one can easily find out a main duct running longitudinally in the figure. Several side branches ramifying from the main duct divide gradually and merge finally into the ductular network. 
The continuity of individual ducts and ductules is fully maintained to every corner.

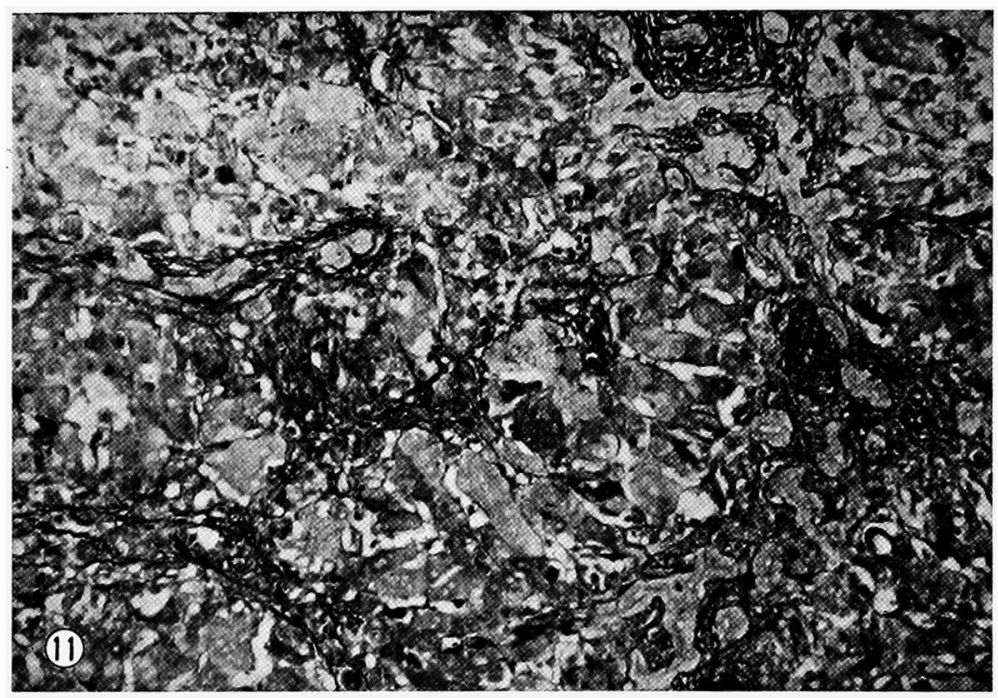

Fig. 11. Photomicrograph of the liver in Case 2.

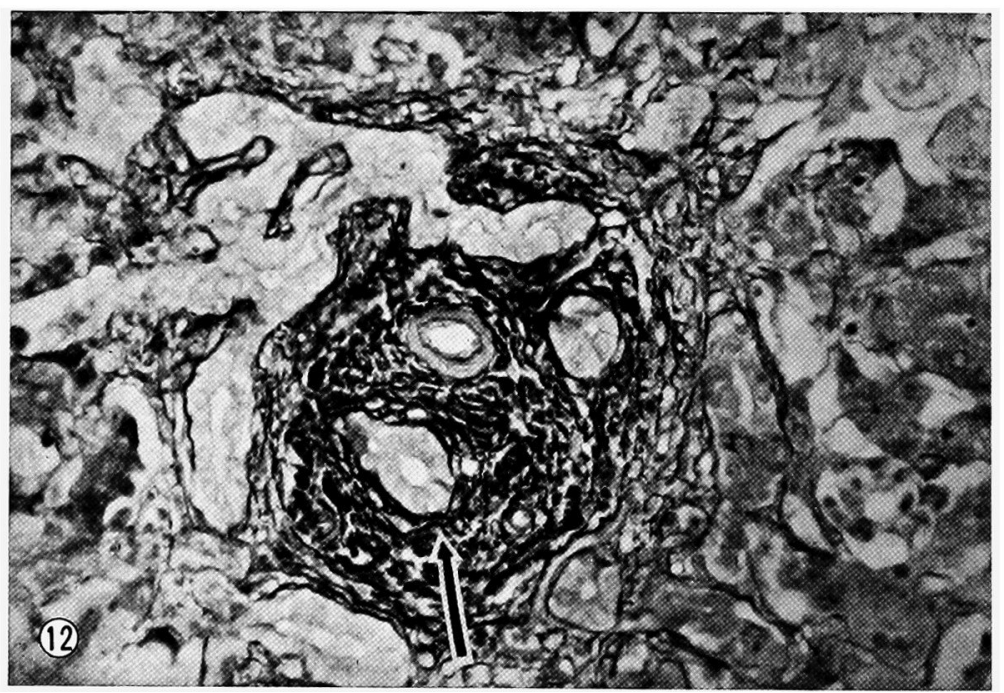

Fig. 12. The main duct is clearly recognized in the dense mass of collagenous tissue (arrow).

Case 3 (group 2). A.O., female, death on the 192nd day of life.

The delivery was full term and normal. The birth weight of the child was $2,600 \mathrm{~g}$. Her stools had not been acholic until the time when she was noticed to be icteric at the age of 3 months. She was treated at a private hospital for 'neonatal hepatitis'. But there was no improvement in her condition. She was 


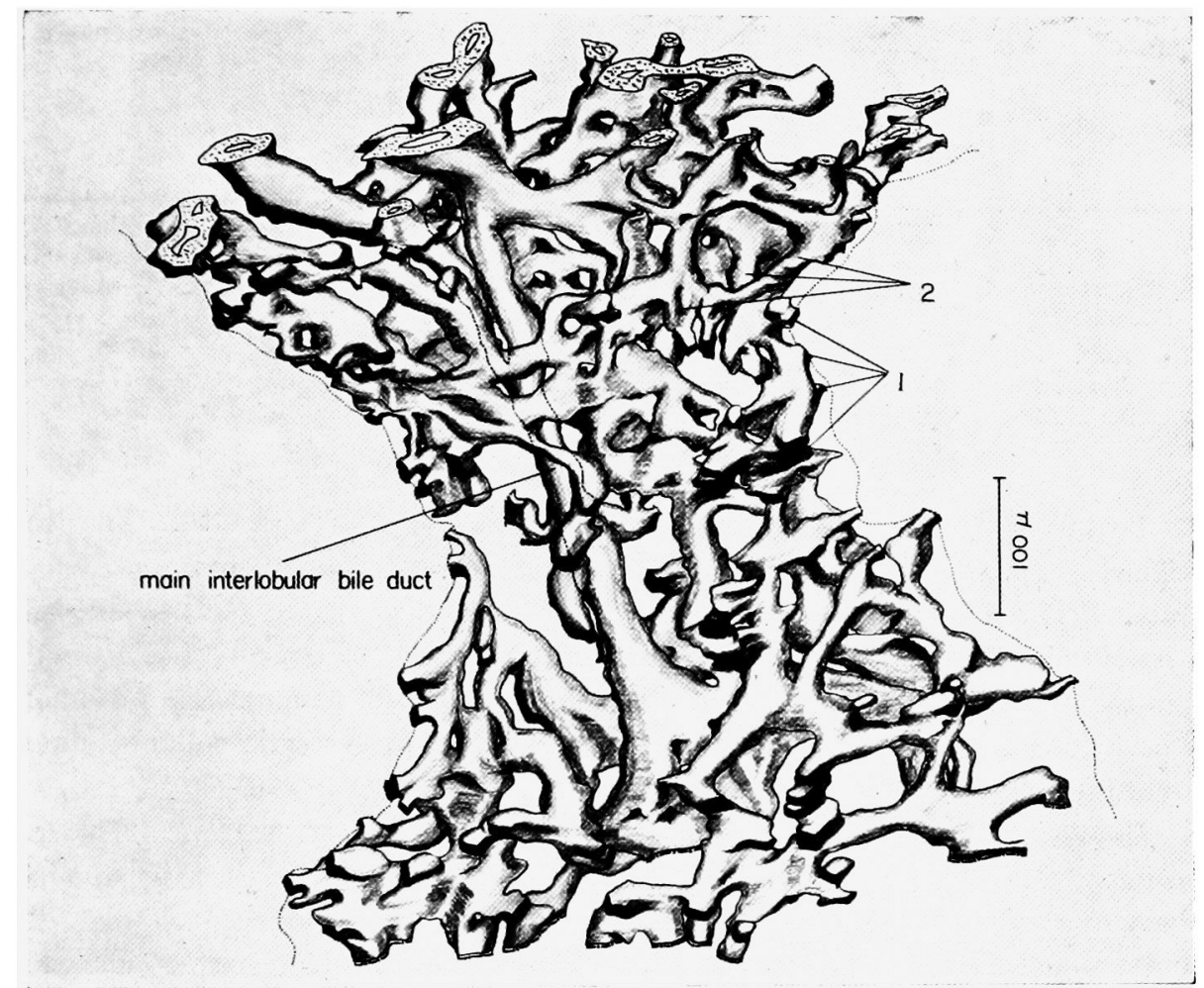

Fig. 13. A graphic reconstruction of the portal tract in Case 2. One can see both abundant proliferation of ductules and main interlobular bile duct easily. 1: connections between proliferated ductules and the limiting plate. 2: proliferating ductular network.

admitted to the Second Surgical Clinic of the Tohoku University Hospital 5 months after birth. On admission, she had marked jaundice and was malnourished and anemic. The liver extended 3 fingers' breadth below the right costal margin. No xanthoma was noted on the skin. Urinalysis showed a positive reaction to bile. The stool was acholic. Examination of the blood disclosed a red cell count of 2.68 millions, $72 \%$ hemoglobin and a white cell count of 16,000 .

The operation performed on the 181st day of life revealed total obliteration of the common bile duct. Conversely, the hepatic duct was dilated like a cyst as a result of accumulation of red-brown muddy substance. The gallbladder was found normal. The liver was dark-green in color and firm in consistency. The malformation was considered to be of the so-called correctable type or of the second type of Kasai's classification with a bile lake at the porta hepatis. Hepaticojejunostomy with Roux-Y anastomosis was carried out. After the operation, the stools were tarry and no bile was proved in them. Severe jaundice continued until her death without any sign of amelioration. High fever lasted after the operation, followed by gradual insufficiency in renal function. She died 10 days after the 
operation. Table 7 presents the results of liver function tests performed before the operation. The liver function was not examined after the operation because of rapid progress of the disease.

TaBLE 7. Liver function tests in Case 3

\begin{tabular}{|c|c|c|c|c|c|c|c|c|}
\hline & \multicolumn{2}{|c|}{ Bilirubin (mg/dl) } & \multirow{2}{*}{ CCFT } & \multirow{2}{*}{$\mathrm{ZTT}$} & \multirow{2}{*}{$\mathrm{TTT}$} & \multirow{2}{*}{\multicolumn{2}{|c|}{ SGOTSGPT }} & \multirow{2}{*}{$\begin{array}{c}\text { Alkaline } \\
\text { phosphatase } \\
\text { (K.A. unit) }\end{array}$} \\
\hline & Total & Direct & & & & & & \\
\hline $\begin{array}{l}\text { Aug. } 4 \\
\text { Aug. } 18 \\
\text { Aug. } 23\end{array}$ & $\begin{array}{c}9.2 \\
12.4 \\
\text { Operation }\end{array}$ & $\begin{array}{l}6.2 \\
9.0\end{array}$ & $\begin{array}{l}(-) \\
(-)\end{array}$ & $\begin{array}{l}1.6 \\
4.8\end{array}$ & $\begin{array}{l}1.2 \\
2.3\end{array}$ & $\begin{array}{l}225 \\
170\end{array}$ & $\begin{array}{r}135 \\
80\end{array}$ & $\begin{array}{l}28.5 \\
44.7\end{array}$ \\
\hline
\end{tabular}

Postmortem examination was performed 2 hours after death. The liver weighed $540 \mathrm{~g}$, was dark-green in color and firm in consistency. It was demonstrated that the anastomosis between the duodenum and dilated hepatic duct was in itself quite excellent and clean. However, there was no trace of bile excretion from the intrahepatic ducts. There were numerous foci of hemorrhagic pneumonia in both lungs. The cause of death was ascribed to systemic collapse due to surgical invasion and pneumonia.

Histological structure of the liver is shown in Figs. 14 and 15. The liver specimen was obtained at autopsy. In Fig. 14, one can see highly advanced biliary cirrhosis. Numerous bile plugs are found in the lobular parenchyma. The lobular structure is emphasized by the development of thick fibrous bands which are stretched around in all directions so as to connect the original portal tracts. These fibrous bands or septa are composed of dense collagenous tissue that is perforated with a dense network of newly formed ductules. Fig. 15 represents a corner of the septum, where a portal tract has been located originally. Here is a mass of ductules anastomosing frequently with one another. It is noteworthy that these ductules are distributed quite irregularly in the area, and that there is no prominent ductal structure indicative of the original main duct. This region was selected for reconstruction of the ductular system.

The result of reconstruction is presented in Fig. 16. Ductular proliferation is much more conspicuous in comparison with that in the foregoing two cases. $L_{d}$ in this case is $75.5 \mathrm{~mm} / \mathrm{mm}^{3}$, which is but a moderate value for the cases in group 2.

As is shown in the figure, newly formed ductules are aggregated to form a ductular labyrinth with numerous anastomoses, and there is a remarkable irregularity in the thickness of the ductules. One can find in places distinct attenuations of ductular branches presumably due to compression by the surrounding fibrous tissue. Moreover, it deserves special attention that this portal tract is obviously deprived of main draining route. The network is composed of irregularly meandering segments of ductules, in which one cannot find such a prominent pathway as has been noticed in the foregoing two cases. 


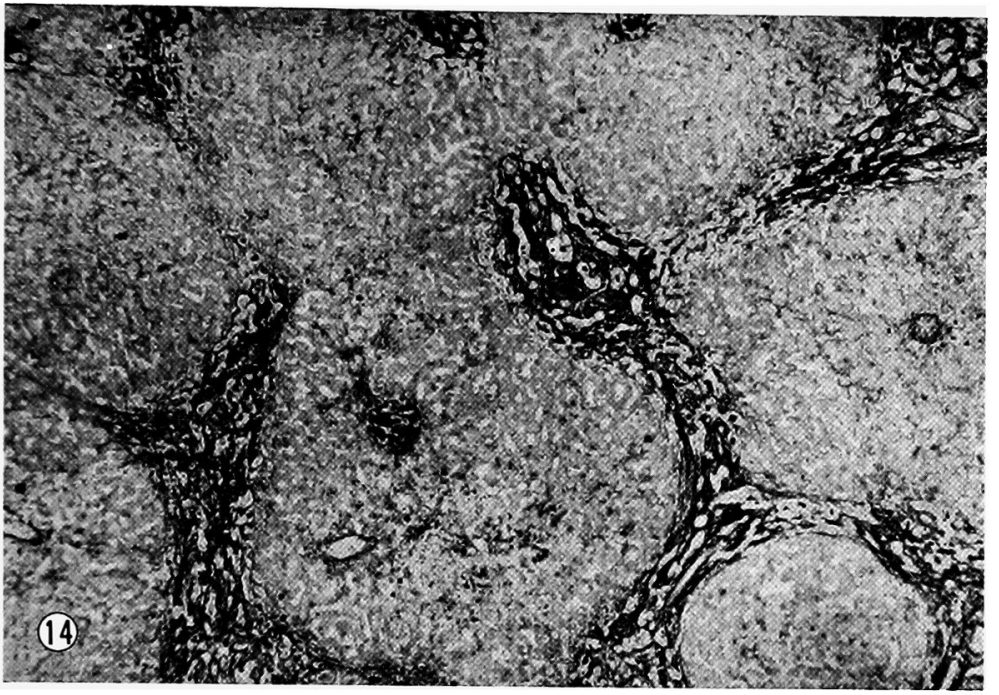

Fig. 14. Photomicrograph of the liver in Case 3.

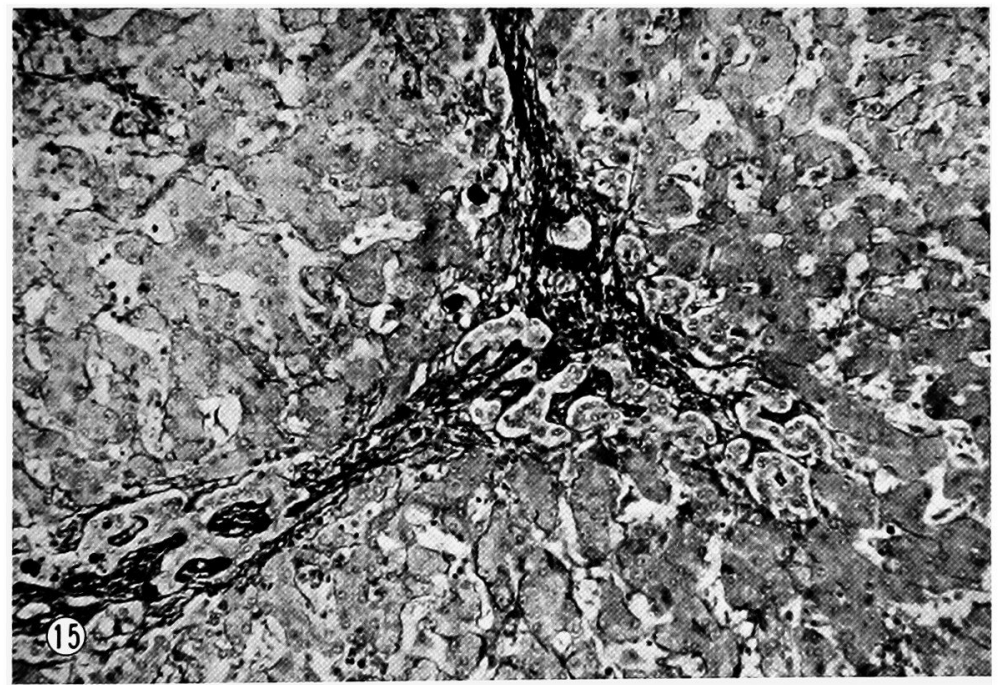

Fig. 15. Microscopical picture of the reconstructed portal tract in Case 3. A mass of ductules anastomosing frequently with one another is distributed irregularly in the area. However, a main duct cannot be recognized.

The graphic reconstructions presented above offer an explanation for the mechanism of intrahepatic bile stasis in advanced biliary cirrhosis. The difference in the structure of the ductular system can be sufficiently recognized between the Cases 1,2 and Case 3. The main ducts are kept intact in the cases selected from group 1 of effective operation. In Case 3, on the contrary, no definite trunk is recognized in the network of ductules in spite of their abundant proliferation. Of 


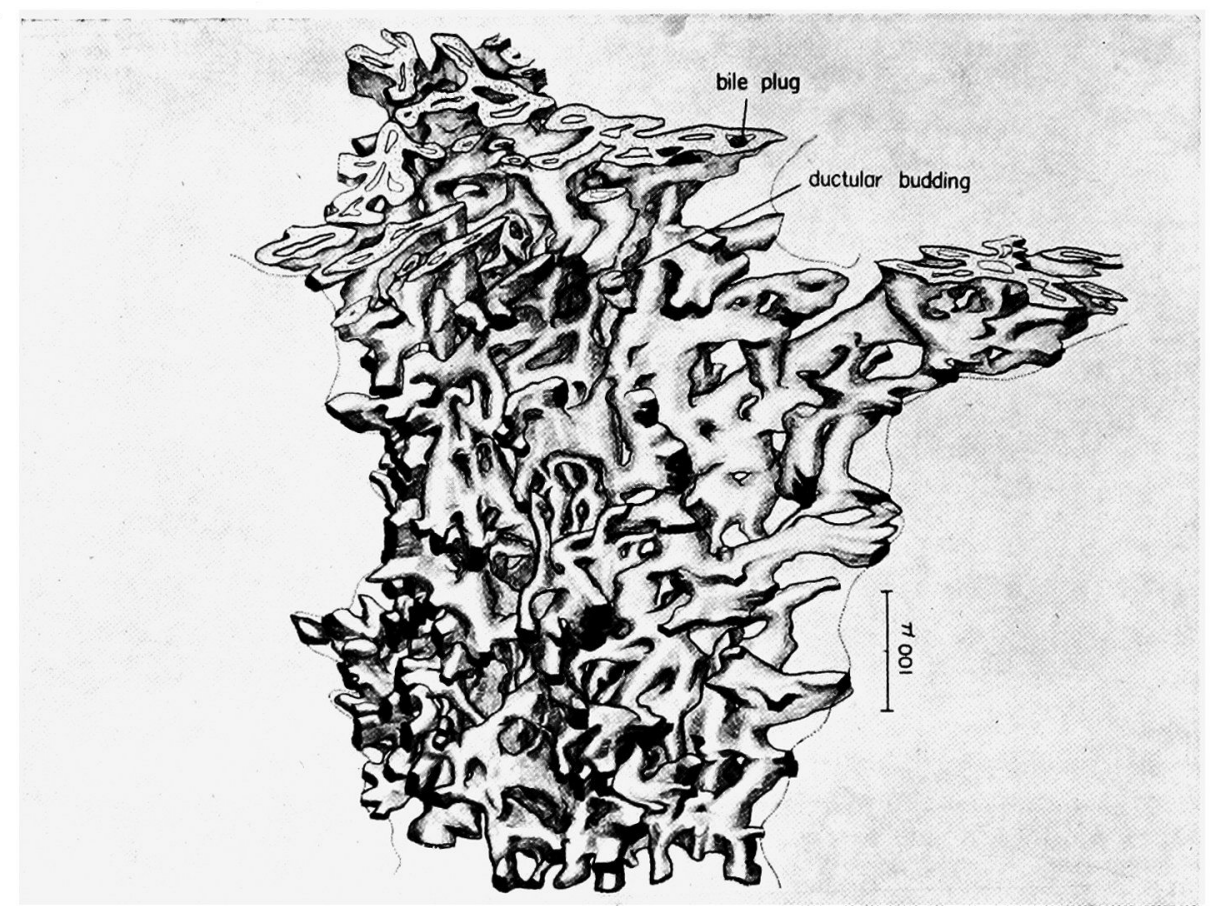

Fig. 16. A graphic reconstruction of the portal tract in Case 3. Note a ductular labyrinth of proliferating ductules with numerous anastomoses. However, one cannot find out an obvious main draining route.

course it is possible that a small amount of bile is conveyed through the network. However, the resistance to bile flow will be very large in such a labyrinth because of the attenuation or meandering of individual ductular segments. It needs no comment that the main duct serves for transportation of bile produced in hepatic parenchyma. Therefore, the maintenance of unobstructed main ducts throughout the liver is the essential prerequisite to intrahepatic bile flow.

The above considerations have disclosed the nature of the intrahepatic factor' as defined in the present study. With the advance of biliary cirrhosis, ductular system undergoes a progressive derangement of its structure, which causes an impediment to intrahepatic bile flow. Thus the intrahepatic factor of bile stasis in congenital biliary atresia can be ascribed to anatomical changes of the draining system in the liver. Consequently, the condition may properly be called intrahepatic bile duct obstruction.

The intrahepatic process will become predominant as hepatic changes progress. There is a possibility of surgical relief, so long as the intrahepatic changes are still below a critical grade. The effect of operation is fully dependent on the grade of hepatic changes in the patient. As has been demonstrated, preservation of main draining routes will be the key to the surgical cure of the disease. 


\section{References}

1) Ahrens, E.H., Harris, R.C. \& MacMahon, H.E. Atresia of the intrahepatic bile ducts. Pediatrics, 1951, 8, 628-647.

2) Sass-Kortsak, A., Bowden, D.H. \& Brown, R. Congenital intrahepatic biliary atresia. Pediatrics, 1956, 17, 383-391.

3) Haas, L. \& Dobbs, R.H. Congenital absence of the intrahepatic bile ducts. Arch. Dis. Childh., 1958, 33, 396-402.

4) Holmes, J.B. Congenital obliteration of the bile ducts. Amer. J. Dis. Child., 1916, 11, $405-431$.

5) Kasai, M., Kimura, S., Asakura, Y., Suzuki, H., Taira, Y. \& Ohashi, E. Surgical treatment of biliary atresia. J. Pediat. Surg., 1968, 3, 665-675.

6) Carlson, E. Salvage of the "noncorrectable" case of congenital extrahepatic biliary atresia. Arch. Surg., 1960, 81, 893-898.

7) Longmire, W.P., Jr. Congenital biliary hypoplasia. Ann. Surg., 1964, 159, 335-343.

8) Takahashi, T. \& Hayama, T. Pathogenesis of so-called intrahepatic cholestasis based on three-dimensional analysis of the cholangiolar system. Tohoku J. exp. Med., 1967, 91, 149-176.

9) Suwa, N., Takahashi, T. \& Sasaki, Y. Histometrical studies of liver cirrhosis by mathematical treatments of linear intercepts on a small number of random histological sections. Tohoku J. exp. Med., 1964, 84, 1-36.

10) Takahashi, T., Orii, T. \& Kaneda, M. Precancerous condition of the human liver. Tohoku J. exp. Med., 1968, 94, 203-224.

11) Arai, S., Machida, A. \& Nakamura, T. Myocardial structure and vascularization of hypertrophied hearts. Tohoku J. exp. Med., 1968, 95, 35-54.

12) Moore, T.C. Congenital atresia of the extrahepatic bile ducts. Report of 31 proved cases. Surg. Gynec. Obstet., 1953, 96, 215-225.

13) Sterling, J.A. Biliary tract morphology and prognosis of biliary atresia. Amer. $J$. Gastroent., 1966, 45, 261-266. 